\title{
Correlation between thoracolumbar curvatures and respiratory function in older adults
}

\author{
This article was published in the following Dove Press journal: \\ Clinical Interventions in Aging \\ 15 March 2017 \\ Number of times this article has been viewed
}

\author{
Nor Najwatul Akmal Ab \\ Rahman' \\ Devinder Kaur Ajit Singh' \\ Raymond Lee ${ }^{2}$ \\ 'Physiotherapy Programme, School \\ of Rehabilitation Sciences, Faculty \\ of Health Sciences, Universiti \\ Kebangsaan Malaysia, Jalan Raja Muda \\ Abdul Aziz, Kuala Lumpur, Malaysia; \\ ${ }^{2}$ School of Applied Sciences, London \\ South Bank University, London, UK
}

Correspondence: Devinder Kaur Ajit Singh

Physiotherapy Programme, School of Rehabilitation Sciences, Faculty of Health Sciences, Universiti Kebangsaan Malaysia, Jalan Raja Muda Abdul Aziz, 50300 Kuala Lumpur, Malaysia

Tel +60 326878003

Fax +60326878199

Email devinder@ukm.edu.my

\begin{abstract}
Aging is associated with alterations in thoracolumbar curvatures and respiratory function. Research information regarding the correlation between thoracolumbar curvatures and a comprehensive examination of respiratory function parameters in older adults is limited. The aim of the present study was to examine the correlation between thoracolumbar curvatures and respiratory function in community-dwelling older adults. Thoracolumbar curvatures (thoracic and lumbar) were measured using a motion tracker. Respiratory function parameters such as lung function, respiratory rate, respiratory muscle strength and respiratory muscle thickness (diaphragm and intercostal) were measured using a spirometer, triaxial accelerometer, respiratory pressure meter and ultrasound imaging, respectively. Sixty-eight community-dwelling older males and females from Kuala Lumpur, Malaysia, with mean (standard deviation) age of 66.63 (5.16) years participated in this cross-sectional study. The results showed that mean (standard deviation) thoracic curvature angle and lumbar curvature angles were $-46.30^{\circ}\left(14.66^{\circ}\right)$ and $14.10^{\circ}\left(10.58^{\circ}\right)$, respectively. There was a significant negative correlation between thoracic curvature angle and lung function (forced expiratory volume in 1 second: $r=-0.23, P<0.05$; forced vital capacity: $r=-0.32, P<0.05)$, quiet expiration intercostal thickness $(r=-0.22, P<0.05)$ and deep expiration diaphragm muscle thickness $(r=-0.21, P<0.05)$. The lumbar curvature angle had a significant negative correlation with respiratory muscle strength $(r=-0.29, P<0.05)$ and diaphragm muscle thickness at deep inspiration $(r=-0.22, P<0.05)$. However, respiratory rate was correlated neither with thoracic nor with lumbar curvatures. The findings of this study suggest that increase in both thoracic and lumbar curvatures is correlated with decrease in respiratory muscle strength, respiratory muscle thickness and some parameters of lung function. Clinically, both thoracic and lumbar curvatures, respiratory muscles and lung function should be taken into consideration in the holistic management of respiratory function among older adults.
\end{abstract}

Keywords: aging, lung function, respiratory muscle thickness, thoracolumbar curvatures

\section{Introduction}

The world's population is aging. On this basis, Malaysia will be categorized as an aging nation over the next one decade or so. In 2008, the census for Malaysia showed that $7 \%$ of its population were aged 60 years and above, ${ }^{1}$ and by 2020 , it will increase to $9.5 \%$ of the country's population. ${ }^{2}$ The growth of an aging population will exhaust the health care system as there will be an increase in the health care financial and clinical resources. ${ }^{3}$

It is well documented that physiological changes take place in multiple organs with aging that include respiratory system ${ }^{4-7}$ and thoracolumbar curvatures..$^{8-11}$ The correlation between respiratory function and thoracolumbar curvatures has been discussed in the literature. ${ }^{12-15}$ A significant correlation between only lumbar curvature angle with forced vital capacity $(\mathrm{FVC} ; r=-0.65), \% \mathrm{FVC}(r=-0.63)$ and forced expiratory volume 
(FEV; $r=-0.50)$ was reported among community-dwelling older females. ${ }^{12}$ In contrast, a significant negative correlation between thoracic curvature angle and percent predicted FEV in 1 second $\left(\% \mathrm{FEV}_{1} ; r=-0.713, P=0.03\right)$ with a significant reduction in lung function was observed in another study. ${ }^{14}$

In most studies, correlation was limited to lung function and thoracic curvatures. ${ }^{13-16}$ The information regarding the correlation between thoracolumbar curvatures (both thoracic and lumbar curvature) and a comprehensive examination of respiratory function (lung function, respiratory muscle strength and thickness) in older adults is limited. This information is important to assist clinicians for effective management and evidence-based practice.

Therefore, this study aimed to examine the correlation between thoracolumbar curvatures and respiratory function among community dwelling older adults.

\section{Materials and methods}

Ethical approval was obtained from the Research Ethical Committee of Universiti Kebangsaan Malaysia (NN-110-2011).

\section{Recruitment of participants}

Sixty-eight participants were recruited via phone calls and they were selected randomly using tables from the name list of members at a senior citizen club in Kuala Lumpur. Interested participants were given an appointment date for a screening session and were screened for inclusion and exclusion criteria. Participants were included in the study if they were $\geq 60$ years old, able to understand and follow commands in Malay or English language or both, had a body mass index (BMI) in the range $18.5-30.0 \mathrm{~kg} / \mathrm{m}^{2}$ and demonstrated lung function test with $\mathrm{FEV}_{1} / \mathrm{FVC} \geq 70 \%$ predicted. Participants were excluded from the study if they were current or former smokers (smoked at least 100 cigarettes in their lifetime but currently not smoking), had any known history of neurological dysfunctions, spinal deformities, cognitive impairment, cardiorespiratory diseases, previous spinal surgery, serious trauma leading to fractures or dislocation of the spine or any pathologies such as tumors, spinal infection, tuberculosis, inflammatory joint disease, rheumatoid conditions, spondylolisthesis, spondylolysis and had unstable medical conditions.

\section{Study procedure}

Prior to the tests, written and verbal information regarding the study was provided and informed written consent was obtained from all participants. Participants' demographic information that included gender, age, weight and height was taken and BMI was calculated. Participants filled their physical activity levels using modified Baecke physical activity questionnaire.

Participants were required to undergo lung function test using a spirometer (Cosmed Pony FX, Rome, Italy), sitting in an upright position comfortably on a chair with a nose clip attached and head slightly elevated. This test was performed based on the recommendations by the American Thoracic Society ${ }^{17}$ and the parameters measured were $\mathrm{FEV}_{1}, \mathrm{FVC}$ and $\mathrm{FEV}_{1} / \mathrm{FVC}$. Respiratory muscle strength was measured using a portable respiratory pressure meter (Micro RPMMicro Medical Limited, Kent, UK) and included maximal inspiratory pressure (MIP) and maximal expiratory pressure (MEP). Participants were requested to sit upright comfortably on a chair with a back rest. MIP was measured at the level of residual volume, lung empty, and MEP was measured at the level of total lung capacity, with lungs full. The technique was repeated five times and participants were allowed to rest for 1-2 minutes in between tests. The mean value of the five readings was taken as the measurement.

A $2 \mathrm{~g}$ triaxial accelerometer (Model 2460; Silicon Designs, Inc., Kirkland, WA, USA) was placed directly on the skin over the sternum (at xiphoid bone) on the area of the chest of the participant to assess respiratory rate. Quiet breathing effort was recorded at a sampling frequency of $10 \mathrm{~Hz}$ for 60 seconds with the participant sitting and leaning back on a chair and arms placed on his/her thighs. Prior to the test, participants were advised and instructed not to move or speak and breathe normally throughout the test.

Thoracolumbar curvature angles were measured and data were recorded using electromagnetic motion tracking system (Patriot; Polhemus, 40 Hercules Dr, Colchester, VT, USA) and performed as reported in an earlier study. ${ }^{8}$ Thoracolumbar curvature angles were measured with participants standing in a relaxed position and with their feet apart to shoulder width. The measurement of thoracolumbar curvatures angles was repeated three times consecutively for each participant. The mean value of the three recordings was taken as the measurement.

Within the same week, participants attended a session of diaphragm, and intercostal muscle thickness was measured using real-time B-mode ultrasonography. A 7.0-10.0 MHz ultrasound linear probe (Siemens Acuson X300; Siemens Medical Solutions, Munich, Germany) was used throughout the procedure with the participants sitting on a chair with back rest. Three images at the end of quiet and at the end of deep breathing were taken by the same operator without removing the ultrasound probe. The images were saved and analyzed 
later using MATLAB ${ }^{\circledR}$ (The Mathworks Inc., Natick, MA, USA) with measurement rounded to $0.10 \mathrm{~cm}$. The mean value from the three images was taken as the measurement.

To capture diaphragm muscle images, ultrasound probe that was coated with ultrasound coupling gel was held perpendicular to the chest wall in the 8th or 9th right intercostal space, between the antero- and mid-axillary lines. Diaphragm muscle thickness was measured by taking five points along the zone of apposition between the outer layer of pleural line and the inner layer of peritoneal layer of the diaphragm muscle. The mean value of 5 points was used as the diaphragm muscle thickness for each image.

Imaging of intercostal muscles was performed with the ultrasound probe that was coated with ultrasound coupling gel placed perpendicular to the skin surface at the 8th posterior right intercostal space at medial right scapula line. Measurement of intercostal muscles was made nearest to $0.10 \mathrm{~cm}$ of 5 points along the muscle fiber between the outer layer and the inner layer of intercostal muscles. The mean value of the 5 points was used as the intercostal muscle thickness for each image.

\section{Data analysis}

Descriptive statistics were used to summarize participants' characteristics and variables measured regarding respiratory functions and thoracolumbar curvature angles. The correlation between thoracolumbar curvature angles and respiratory function parameters was analyzed using Pearson's correlation test (for normally distributed data) and Spearman's rank test (for not normally distributed data).

\section{Results}

Participants' characteristics are summarized in Table 1. Participants were between 60 and 78 years' old. The mean thoracic curvature and lumbar curvature angles were 46.30 (14.66) and 14.10 (10.58) degrees, respectively, as shown in Table 2.

The summary of the respiratory muscle strength, respiratory rate, lung function and respiratory muscle thickness results is shown in Table 2. Mean respiratory rate was

Table I Characteristics of participants

\begin{tabular}{ll}
\hline Variables & $\begin{array}{l}\text { Mean (standard } \\
\text { deviation) }\end{array}$ \\
\hline Mean age (years) & $66.63(5.16)$ \\
Mean BMI $\left(\mathrm{kg} / \mathrm{m}^{2}\right)$ & $25.04(3.01)$ \\
Gender & \\
$\quad$ Female, $\mathrm{n}=48(\%)$ & 70.60 \\
$\quad$ Male, $\mathrm{n}=20(\%)$ & 29.40 \\
Physical activity level (score) & $7.45(0.95)$ \\
\hline
\end{tabular}

Abbreviation: BMI, body mass index.
Table 2 Mean and standard deviation of thoracolumbar curvatures angle, respiratory muscle strength, respiratory rate, lung functions parameters and respiratory muscles thickness

\begin{tabular}{|c|c|}
\hline Variables & $\begin{array}{l}\text { Mean (standard } \\
\text { deviation) }\end{array}$ \\
\hline Thoracic curvature angle $\left({ }^{\circ}\right)$ & $-46.30(14.66)$ \\
\hline Lumbar curvature angle $\left({ }^{\circ}\right)$ & $14.10(10.58)$ \\
\hline Mean respiratory rate (bpm) & $19.62(3.88)$ \\
\hline \multicolumn{2}{|l|}{ RMS } \\
\hline Percentage predicted MIP (\%) & $84.74(30.96)$ \\
\hline Percentage predicted MEP (\%) & $93.09(35.66)$ \\
\hline Predicted RMS & $88.91(29.66)$ \\
\hline \multicolumn{2}{|l|}{ Lung function (\%) } \\
\hline Predicted FEV, & $85.75(26.11)$ \\
\hline Predicted FVC & 80.31 (16.27) \\
\hline $\mathrm{FEV}_{1} / \mathrm{FVC}$ & $85.26(7.25)$ \\
\hline \multicolumn{2}{|l|}{ Diaphragm muscle thickness $(\mathrm{cm})$} \\
\hline End of quiet inspiration & $0.29(0.07)$ \\
\hline End of quiet expiration & $0.21(0.05)$ \\
\hline End of deep inspiration & $0.54(0.14)$ \\
\hline End of deep expiration & $0.21(0.05)$ \\
\hline Quiet thickening fraction & 1.38 \\
\hline Deep thickening fraction & 2.57 \\
\hline \multicolumn{2}{|l|}{ Intercostal muscle thickness (cm) } \\
\hline End of quiet inspiration & $0.54(0.11)$ \\
\hline End of quiet expiration & $0.62(0.13)$ \\
\hline End of deep inspiration & $0.52(0.11)$ \\
\hline End of deep expiration & $0.65(0.14)$ \\
\hline Quiet thickening fraction & 0.87 \\
\hline Deep thickening fraction & 0.80 \\
\hline
\end{tabular}

Notes: Thoracic curvature angle (thoracic kyphosis) is reported as negative, reflecting a convex curvature, whilst, lumbar curvature angle (lumbar lordosis) is reported as positive, reflecting a concave curvature.

Abbreviations: MIP, maximal inspiratory pressure; MEP, maximal expiratory pressure; $\mathrm{FEV}_{1}$, forced expiratory volume in I second; FVC, forced vital capacity; RMS, respiratory muscle strength.

19.62 breaths per minute (bpm). Mean values for MIP and MEP and all lung function parameters were above $80 \%$ of their predicted values. Most of the respiratory function parameters for male participants were higher compared to those for female participants. For respiratory muscle strength pressures, none of the participants were below the lower limit of the normal range. Diaphragm muscle thickness was $86 \%$ thicker at the end of deep inspiration than at the end of quiet inspiration. Differences in diaphragm thickness during quiet and deep breathing were $0.08 \mathrm{~cm}$ and $0.33 \mathrm{~cm}$, respectively. During both types of breathing activities (quiet breathing and deep breathing), diaphragm muscle thickness at the end of expiration was similar $(0.21 \mathrm{~cm})$. Diaphragm thickening ratio during deep breathing was almost two times the ratio during quiet breathing. During both quiet and deep breathing activities, intercostal muscle was thicker at the end of expiration $(0.62-0.65 \mathrm{~cm})$ than at the end of inspiration $(0.52-0.54 \mathrm{~cm})$. 
Table 3 Correlation between thoracolumbar curvatures and respiratory functions

\begin{tabular}{|c|c|c|c|c|}
\hline \multirow[t]{2}{*}{$\begin{array}{l}\text { Respiratory } \\
\text { functions }\end{array}$} & \multicolumn{2}{|c|}{$\begin{array}{l}\text { Thoracic } \\
\text { curvature }\end{array}$} & \multicolumn{2}{|c|}{$\begin{array}{l}\text { Lumbar } \\
\text { curvature }\end{array}$} \\
\hline & $r / r_{\mathrm{s}}$ & $P$-value & $r / r_{\mathrm{s}}$ & $P$-value \\
\hline Respiratory rate & -0.136 & 0.134 & -0.107 & 0.193 \\
\hline \multicolumn{5}{|l|}{ Lung function test } \\
\hline FEV & -0.232 & $0.029 *$ & 0.057 & 0.322 \\
\hline FVC & -0.317 & $0.004^{*}$ & -0.021 & 0.433 \\
\hline FEV,/FVC (\%) & 0.15 & 0.111 & 0.053 & 0.333 \\
\hline MIP (\% predicted) & 0.129 & 0.408 & -0.244 & $0.022^{*}$ \\
\hline MEP (\% predicted) & 0.023 & 0.427 & -0.284 & $0.010 *$ \\
\hline \multicolumn{5}{|l|}{ Diaphragm thickness } \\
\hline DQI & -0.137 & 0.133 & -0.128 & 0.150 \\
\hline DQE & -0.193 & 0.057 & -0.149 & 0.112 \\
\hline DDI & -0.163 & 0.093 & -0.222 & $0.035^{*}$ \\
\hline DDE & -0.209 & $0.043^{*}$ & -0.051 & $0.24 I$ \\
\hline \multicolumn{5}{|l|}{ Intercostal thickness } \\
\hline IQI & -0.183 & 0.067 & -0.022 & 0.429 \\
\hline IQE & -0.215 & $0.039 *$ & -0.013 & 0.459 \\
\hline IDI & -0.182 & 0.068 & -0.091 & 0.230 \\
\hline IDE & -0.151 & 0.110 & 0.011 & 0.464 \\
\hline
\end{tabular}

Note: *Significant level at alpha, $P<0.05$.

Abbreviations: $r$, Pearson's correlation; $r$, Spearman's rho; DQI, diaphragm thickness during quiet inspiration; DQE, diaphragm thickness during quiet expiration; DDI, diaphragm thickness during deep inspiration; DDE, diaphragm thickness during deep expiration; IQI, intercostal thickness during quiet inspiration; IQE, intercostal thickness during quiet expiration; IDI, intercostal thickness during deep inspiration; IDE, intercostal thickness during deep expiration; MIP, maximal inspiratory pressure; MEP, maximal expiratory pressure; $\mathrm{FEV}_{1}$, forced expiratory volume in I second; FVC, forced vital capacity.

Correlation results between thoracolumbar curvatures and respiratory functions among participants are shown in Table 3. Lung function parameters had a significant $(P<0.05)$ negative correlation with thoracic curvature angles $\left(\mathrm{FEV}_{1}\right.$ : $r=-0.232$; FVC: $r=-0.317)$. No significant correlations were demonstrated between lung function parameters and lumbar curvature. Lumbar curvature angle was significantly correlated with $\operatorname{MIP}\left(r_{\mathrm{s}}=-0.244\right)$ and $\operatorname{MEP}\left(r_{\mathrm{s}}=-0.283\right)$ (percentage predicted) with weak to moderate negative correlation.

Significant correlation was only shown at deep breathing for diaphragm muscle thickness with lumbar curvature and intercostal muscle thickness during quiet expiration with thoracic curvature. There was a significant $(P<0.05)$ negative correlation between lumbar curvature and diaphragm muscle thickness during deep inspiration, while thoracic curvature was significantly correlated with diaphragm muscle thickness during deep expiration and with intercostal muscle thickness during quiet expiration.

\section{Discussion}

The aim of the present study was to examine the correlation between thoracolumbar curvatures and respiratory and lung functions among older adults. In the present study, we found that thoracic curvature was correlated significantly with lung functions $\left(\mathrm{FEV}_{1}\right.$ and $\left.\mathrm{FVC}\right)$ and respiratory muscle thickness (diaphragm thickness during deep expiration [DDE]). However, lumbar curvature was significantly correlated with respiratory muscle strength (MIP and MEP) and diaphragm muscle thickness during deep inspiration. These findings demonstrated for the first time that an increase in both thoracic and lumbar curvatures was correlated with decrease in respiratory muscle strength, respiratory muscle thickness and some parameters of lung functions.

Thoracic curvature angle among older adults using a similar method was reported to be 46.95 (11.41) degrees and significantly larger compared to younger adults. ${ }^{8}$ Consistent with the literature, the results of thoracic curvature angles among older adults in the present study suggest an increase in thoracic curvature with aging. Asymmetrical degenerative discs, reduced musculature tone, intrinsic hypermobility and endocrine-related collagen weakening are some of the possible reasons for increased thoracic kyphosis among older adults.., 18 Lumbar curvature angles in the present study were 52\% larger compared to the study by Singh et al. ${ }^{8}$ This might be due to the larger number of females in this study. Larger lumbar curvature angles in females have been reported previously. ${ }^{19}$

The mean respiratory rate (19.62 bpm) measured using a triaxial accelerometer in the present study was found to be in the normal range (16-24 bpm) for older adults. ${ }^{20}$ In a previous study, a $6 \%-13 \%$ increase in respiratory efforts was reported in older adults (age 70 years and above). ${ }^{21}$ Mean MIP and MEP values were used as tools of measurements for respiratory muscle strength among older adults and the results were $63.15 \mathrm{~cm} \mathrm{H}_{2} \mathrm{O}$ and $76.13 \mathrm{~cm} \mathrm{H}_{2} \mathrm{O}$, respectively. These results show higher values, suggesting higher respiratory muscle strength compared to previous studies among older adults. 5,22,23 This may be due to the fact that participants in the present study were represented by both males and females and were younger active community-dwelling older adults. In the study by Simões et al, the participants were older females from residential institutions. ${ }^{22}$

The data in the present study showed that lung functions among older adults were $\sim 20 \%$ lower compared to a sedentary younger population in Thailand. ${ }^{24}$ These results are expected as the chest wall becomes stiffer in relation to calcification and other structural changes within the rib cage with aging. ${ }^{7,25}$ As a result, reduction in lung compliance, diminished lung elastic recoil and increased functional residual capacity among older adults ${ }^{26}$ decreased the vital capacity and expiratory flow rate. ${ }^{4}$ 
The present data also indicated that diaphragm muscle thickness during quiet breathing was within the normal range in comparison to the data reported previously. ${ }^{27-29}$ Although diaphragm muscle thickness in the present study was within the normal range, it was still less in normal conditions of quiet breathing $(0.33 \mathrm{~cm})$ as suggested in a recent study. ${ }^{30}$ In addition to aging process, a decline in physical activity of the participants in the present study could have contributed to the less than normal values. In a study by Summerhill et al, it was found that the active group had twice the diaphragm muscle thickness compared to the inactive group (less than three exercise sessions per week). ${ }^{31}$

The intercostal muscle thickness was found to be $0.52 \mathrm{~cm}$ during quiet inspiration and $0.62 \mathrm{~cm}$ during quiet expiration. This suggests that the intercostal muscles are thicker during quiet expiration. This result is supported by previous reports that intercostal muscles were thicker during expiration compared to inspiration. ${ }^{32}$ These results are possible due to the fact that the mean cross-sectional area of expiratory internal intercostal muscles is larger compared to inspiratory internal and external intercostal muscles..$^{33}$

The present study provides a comprehensive correlation between both thoracic and lumbar curvatures and respiratory function that includes lung and respiratory muscle function. Lumbar curvature was found to be significantly correlated between diaphragm muscle thickness during deep inspiration and respiratory muscle strength. Diaphragm muscle is the main muscle of inspiration ${ }^{34,35}$ and the main attachment of the diaphragm muscle is at the lumbar spine. ${ }^{12}$ Thus, a correlation between diaphragm muscle thickness and lumbar curvatures may be possible.

Measurements of respiratory muscle strength in the present study can be considered as gross muscle strength that included diaphragm and intercostal and accessory muscles. It may also have included trunk and abdomen muscles, especially the transverse abdominal muscles that are known to be involved in respiratory activities. ${ }^{36}$ Contraction of transverse abdominal muscles results in increased intra-abdominal pressures, which may straighten the lumbar spine. ${ }^{37}$ This may be another reason for the correlation between respiratory muscle strength and lumbar curvature angles.

In addition, there was a significant negative correlation between thoracic curvature angles and lung function. Any increase in thoracic curvatures can result in a decrease in lung volumes due to decrease in anterior-posterior diameter of the chest wall. ${ }^{16}$ Thoracic curvature was significantly associated with intercostal muscle thickness during expiration $(r=-0.215, P=0.039)$ but not during quiet inspiration.
This can be explained by the fact that primary action of inspiration is by parasternal intercostal muscle and expiratory action is a passive activity after inspiration. The expiratory internal intercostal muscle runs obliquely and dorsally from each rib to neighboring ribs below, and during contractions these muscles act to lower the ribs. ${ }^{38}$ Note that the ribs are attached to the thoracic vertebras and the origin and insertion of intercostal muscles are at the ribs. Thus, changes in thoracic curvatures can be associated with the intercostal muscle thickness. However, the interaction was demonstrated only with thickness of intercostal muscles during expiration, probably because expiratory intercostal muscle mass is larger compared to inspiratory intercostal muscles. ${ }^{33}$

In addition, thoracic curvatures were found to be correlated with diaphragm thickness during deep expiration $(r=-0.209$, $P=0.043)$ but not during deep inspiration $(r=-0.163$, $P=0.093)$. This can be explained by the action of hemidiaphragm and abdominal muscles. In older adults, to maintain required lung volume, the diaphragm needs to be lower and more flat to compromise the rigid chest wall. ${ }^{39}$ Moreover, the action of abdominal muscles during deep expiration leads to inward pulling of the abdominal wall. ${ }^{40}$ This results in a lower and more flattened diaphragm. ${ }^{40}$ No correlation was found between thoracolumbar curvature angles and respiratory rates. It is probably because respiratory rate is largely related to ventilation efforts such as tidal volume, minute ventilation and elastic recoil. These parameters are not directly linked to thoracolumbar curvatures.

This study has contributed to the literature in two ways. First, this study has demonstrated that those increases in both thoracic and lumbar curvatures were associated with decrease in respiratory muscle strength, respiratory muscle thickness and some parameters of lung functions. The present study results suggest that improvements in lung function among older adults, thoracic and lumbar curvatures, respiratory muscle strength and mass should be considered. This study has also provided a novel, innovative and reliable method of assessing respiratory rates using an accelerometer and respiratory (diaphragm and intercostal) muscle thickness using ultrasound imaging. These techniques will be useful for both clinical and research settings as these are noninvasive in nature.

The limitation of the present study was that the data collected were confined at a single citizen club at a suburban area. Hence, the study results may not be applicable to community-dwelling older adults living in rural areas and to older adults living in residential institutions. The difference in the levels of physical activity and lifestyles among older 
adults living in different geographical areas can influence the results.

\section{Conclusion}

In summary, this study has provided a comprehensive picture of the association between thoracolumbar curvature, respiratory and lung functions among older adults. Also, an increase in thoracolumbar curvatures was correlated with decrease in respiratory muscle strength, respiratory muscle thickness and some parameters of lung functions. Clinically, both thoracic and lumbar curvatures, respiratory muscle and lung functions should be taken into consideration in the holistic management of respiratory functions among older adults. It is sincerely believed that the information from this study will assist in further improvements in clinical management of thoracolumbar curvature changes and respiratory functions in older adults.

\section{Acknowledgments}

This study was funded by Fundamental Research Grant Scheme (UKM-NN-03-FRGS0166-2010) from the Ministry of Higher Education, Malaysia, through Universiti Kebangsaan Malaysia. We would like to thank all participants and the management of the senior citizens' club, Kuala Lumpur, and Dewan Bandaraya Kuala Lumpur for their participation and assistance.

\section{Author contribution}

All authors contributed toward data analysis, drafting and revising the paper and agree to be accountable for all aspects of the work.

\section{Disclosure}

The authors report no conflicts of interest in this work.

\section{References}

1. WHO. World Health Statistics. Geneva: WHO; 2010. Available from: http://www.who.int/gho/publications/world_health_statistics/ EN_WHS10_Full.pdf. Accessed November 25, 2010.

2. Ong FS. Ageing and long-term care. In: Ageing in Malaysia: A Review of National Policies and Programmes (Chapter 4). Singapore: ISEAS-Yusof Ishak Institute; 2010:107-149.

3. Janssens JP. Aging of the respiratory system: impact on pulmonary function tests and adaptation to exertion. Clin Chest Med. 2005;26(3): 469-484.

4. Height B, Gibson F, editors. Burnside's Working with Older Adults: Group Process and Techniques. 4th ed. Boston: Jones and Barlett Publishers; 2005.

5. Buchman AS, Boyle PA, Wilson RS, Gu L, Bienias JL, Bennett DA. Pulmonary function, muscle strength and mortality in old age. Mech Ageing Dev. 2008;129(11):625-631.

6. Watsford ML, Murphy AJ, Pine MJ. The effects of ageing on respiratory muscle function and performance in older adults. $J$ Sci Med Sport. 2007;10(1):36-44.
7. Simões RP, Auad MA, Diosíno J, Mazzonetto M. Influence of age and sex on respiratory muscle strength. Fisioter Pesqu. 2007;14(1):36-41.

8. Singh DK, Bailey M, Lee R. Biplanar measurement of thoracolumbar curvature in older adults using an electromagnetic tracking device. Arch Phys Med Rehabil. 2010;91(1):137-142.

9. Bartynski WS, Heller MT, Grahovac SZ, Rothfus WE, Kurs-Lasky M. Severe thoracic kyphosis in the older patient in the absence of vertebral fracture: association of extreme curve with age. AJNR Am J Neuroradiol. 2005;26(8):2077-2085.

10. Nishiwaki Y, Kikuchi Y, Araya K, et al. Association of thoracic kyphosis with subjective poor health, functional activity and blood pressure in the community-dwelling elderly. Environ Health Prev Med. 2007;12(6):246-250.

11. Takeda N, Kobayashi T, Atsuta Y, Matsuno T, Shirado O, Minami A. Changes in the sagittal spinal alignment of the elderly without vertebral fractures: a minimum 10-year longitudinal study. J Orthop Sci. 2009; 14(6): 748-753.

12. Horie J, Murata S, Inoue $\mathrm{Y}$, et al. A study of the influence of the pulmonary function on the angles of thoracic kyphosis and lumbar lordosis in community-dwelling elderly women. J Phys Ther Sci. 2009; 21(2):169-172.

13. Di Bari M, Chiarlone M, Matteuzzi D, et al. Thoracic kyphosis and ventilator dysfunction in unselected older persons: an epidemiological in Dicomano, Italy. J Am Geriatr Soc. 2004;52(6):909-915.

14. Lombardi I Jr, Oliveira LM, Mayer AF, Jardim JR, Natour J. Evaluation of pulmonary function and quality of life in women with osteoporosis. Osteoporos Int. 2005;16(10):1247-1253.

15. Ghanbarzadeh M, Mehdipour A. Study and influence of exercise program on respiratory function of adults with kyphosis. Acta Bioeng Biomech. 2009;11(1):11-17.

16. Chun EM, Suh SW, Modi HN, Kang EY, Hong SJ, Song HR. The change in ratio of convex and concave lung volume in adolescent idiopathic scoliosis: a 3D CT scan based cross sectional study of effect of severity of curve on concave and convex lung volumes in 99 cases. Eur Spine J. 2008;17(2):224-229.

17. Miller MR, Hankinson J, Brusasco V, et al; ATS/ERS Task Force. Standardisation of spirometry. Eur Respir J. 2005;26(2):319-338.

18. Hinman MR. Comparison of thoracic kyphosis and postural stiffness in younger and older women. Spine J. 2004;4(4): 413-417.

19. Youdas JW, Hollman JH, Krause DA. The effects of gender, age, and body mass index on standing lumbar curvature in persons without current low back pain. Physiother Theory Pract. 2006;22(5): 229-237.

20. McFadden JP, Price RC, Eastwood HD, Briggs RS. Raised respiratory rate in elderly patients: a valuable physical sign. $\mathrm{Br}$ Med J (Clin Res Ed). 1982;284(6316):626-627.

21. Johnson BD, Dempsey JA. Demand vs. capacity in the aging pulmonary system. Exerc Sport Sci Rev. 1991;19:171-210.

22. Simões RP, Castello V, Auad MA, Dionísio J, Mazzonetto M. Prevalence of reduced respiratory muscle strength in institutionalized elderly people. Sao Paulo Med J. 2009;127(2):78-83.

23. Johan A, Chan CC, Chia HP, Chan OY, Wang YT. Maximal respiratory pressure in adult Chinese, Malays and Indians. Eur Respir J. 1997; 10(12):2825-2828.

24. Dumrongchua J, Khrisanapant W, Tunkamnerdthai O. Respiratory muscle strength and pulmonary function in sedentary Thais. Proc Grad Res Conf. 2012:829-837.

25. Krumpe PE, Knudson RJ, Parsons G, Reiser K. The aging respiratory system. Clin Geriatr Med. 1985;1(1):143-175.

26. Janssens JP, Pache JC, Nicod LP. Physiological changes in respiratory function associated with ageing. Eur Respir J. 1999;13(1): 197-205.

27. Harper CJ, Shahgholi L, Cieslak K, Hellyer NJ, Strommen JA, Boon AJ. Variability in diaphragm motion during normal breathing, assessed with B-mode ultrasound. J Orthop Sports Phys Ther. 2013;43(12): 927-931. 
28. Gottesman E, McCool FD. Ultrasound evaluation of the paralyzed diaphragm. Am J Respir Crit Care Med. 1997;155(5):1570-1574.

29. Ueki J, De Bruin PF, Pride NB. In vivo assessment of diaphragm contraction by ultrasound in normal subjects. Thorax. 1995;50(11): 1157-1161.

30. Boon AJ, Harper CJ, Ghahfarokhi LS, Strommen JA, Watson JC, Sorenson EJ. Two dimensional ultrasound imaging of the diaphragm: quantitative values in normal subjects. Muscle Nerve. 2013; 47(6):884-889.

31. Summerhill EM, Angov N, Garber C, McCool FD. Respiratory muscle strength in the physically active elderly. Lung. 2007;185(6):315-320.

32. Diab KM, Shalabi A, Sevastik JA, Güntner P. A method for morphometric study of the intercostal muscles by high-resolution ultrasound. Eur Spine J. 1998;7(3):224-228.

33. Gayan-Ramirez G, Decramer M. Biology of the respiratory muscles. In: Hamid Q, Shannon J, Martin J, editors. Physiologic Basis of Respiratory Disease. Hamilton: BC Decker; Inc; 2005:227-287.

34. Hess D, MacIntyre NR, Galvin WF, Mishoe SC, Adams, editors. Respiratory Care: Principle and Practice. 2nd ed. Boston: Jones \& Bartlett Learning, LLC; 2012.
35. Ratnovsky A, Elad D, Halpern P. Mechanics of respiratory muscles. Respir Physiol Neurobiol. 2008;163(1-3):82-89.

36. Abe T, Kusuhara N, Yoshimura N, Tomita T, Easton PA. Differential respiratory activity of four abdominal muscles in humans. $J \mathrm{Appl}$ Physiol. 1996;80(4):1379-1389.

37. Richardson C, Hodges PW, Hides J. Therapeutic Exercise for Lumbopelvic Stabilization. 2nd ed. Edinburgh: Churchill Livingstone; 2004.

38. De Troyer A. Biology of the respiratory muscles. In: Hamid Q, Shannon J, Martin J, editors. Physiologic Basis of Respiratory Disease. Hamilton: BC Decker, Inc; 2005:227-287.

39. Suwatanapongched T, Gierada DS, Slone RM, Pilgram TK, Tuteur PG. Variation in diaphragm position and shape in adults with normal pulmonary function. Chest. 2003;123(6):2019-2027.

40. De Troyer A. The respiratory muscle. In: Crystal RG, editor. The Lung: Scientific Foundation. Philadelphia: Lippincott Raven; 1997: 1203-1215.
Clinical Interventions in Aging

\section{Publish your work in this journal}

Clinical Interventions in Aging is an international, peer-reviewed journal focusing on evidence-based reports on the value or lack thereof of treatments intended to prevent or delay the onset of maladaptive correlates of aging in human beings. This journal is indexed on PubMed Central, MedLine,

\section{Dovepress}

CAS, Scopus and the Elsevier Bibliographic databases. The manuscript management system is completely online and includes a very quick and fair peer-review system, which is all easy to use. Visit http://www.dovepress. com/testimonials.php to read real quotes from published authors. 